\title{
Bioprosthetic mitral valve effective orifice area using 4D flow cardiac magnetic resonance derived time velocity integral. An in vitro comparison with Doppler Echocardiography
}

Dimitrios Maragiannis, Matthew Jackson, Stephen Igo, Karen Chin, Kyle Autry, Mohamad G Ghosn, Dipan J Shah, Stephen H Little

From 18th Annual SCMR Scientific Sessions

Nice, France. 4-7 February 2015

\section{Background}

4D Flow Cardiac Magnetic Resonance (CMR) is a novel imaging modality to assess bioprosthetic mitral valve (BMV) function. We describe a new, 4D Flow derived velocity time integral (TVI) based method to assess effective orifice area (EOA) for BMVs.

\section{Methods}

In our MRI-compatible circulatory loop 4 stented porcine BMVs $(27,29,31,33 \mathrm{~mm})$ underwent CMR with a 1.5T Siemens scanner. The valves were evaluated at forward stroke volumes of 70,90 and $110 \mathrm{ml}$ at a beat rate of 70bpm. We plotted instantaneous peak velocities and calculated TVI for each scenario. 4D CMR-EOA was

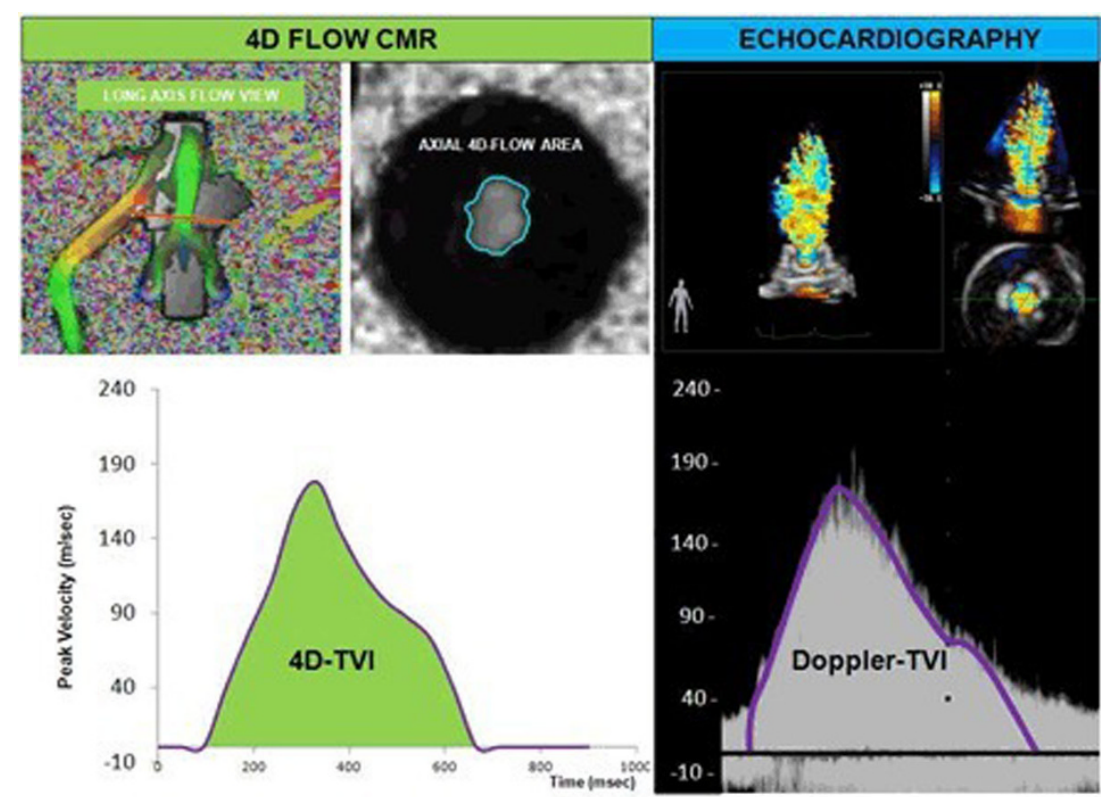

Figure 1

Cardiology, Houston Methodist Hospital, Houston, TX, USA

(c) 2015 Maragiannis et al; licensee BioMed Central Ltd. This is an Open Access article distributed under the terms of the Creative 
calculated by dividing the forward stroke volume measured by our high fidelity flow transducers with the calculated TVI. Doppler derived EOA was calculated identically using the Doppler derived TVI.

\section{Results}

4D CMR-EOA was successfully calculated in a total number of 12 tests. 4D Flow CMR-EOA revealed a strong correlation when compared with Doppler derived EOA $(r=0.985, p<0.001)$ and the mean difference was $-0.1 \pm 0.05 \mathrm{~cm}^{2}$ between the two methods. Calculated CMR-TVI by our method correlated well with Doppler derived TVI $(\mathrm{r}=0.99, \mathrm{p}<0.001$ and mean difference 3.2 $\pm 1.97 \mathrm{~cm}$ ).

\section{Conclusions}

Our study demonstrated the feasibility of 4D Flow CMR to evaluate bioprosthetic valve EOA with the use of velocity encoded CMR data from 4D Flow Software analysis. Our data showed high agreement with Doppler EOA calculations, demonstrating a potential for 4D Flow CMR in bioprosthetic valve evaluation.

\section{Funding}

American Heart Association grant \#11BGIA5840008.
doi:10.1186/1532-429X-17-S1-P336

Cite this article as: Maragiannis et al:: Bioprosthetic mitral valve effective orifice area using $4 \mathrm{D}$ flow cardiac magnetic resonance derived time velocity integral. An in vitro comparison with Doppler

Echocardiography. 2015 17(Suppl 1):P336.
Submit your next manuscript to BioMed Central and take full advantage of:

- Convenient online submission

- Thorough peer review

- No space constraints or color figure charges

- Immediate publication on acceptance

- Inclusion in PubMed, CAS, Scopus and Google Scholar

- Research which is freely available for redistribution

Submit your manuscript at www.biomedcentral.com/submit
C Biomed Central 